\section{Penilaian Bentuk Adaptasi Masyarakat Terhadap Hunian di Kawasan Rawan Rob dan Banjir Kelurahan Kemijen}

\author{
Aufa Dirgahayu Kencana*, Nany Yuliastuti \\ Departemen Perencanaan Wilayah dan Kota, Fakultas Teknik, Universitas Diponegoro
}

\begin{abstract}
Abstrak. Kelurahan Kemijen terletak di Kota pesisir Semarang memiliki tingkat kerentanan bencana yang tinggi. Tingginya tingkat kerentanan bencana tersebut memaksa orang untuk beradaptasi misalnya adalah dengan meninggikan rumah mereka meskipun warga Kelurahan Kemijen didominasi oleh masyarakat berpenghasilan rendah (MBR). Tujuan dari penelitian ini adalah untuk menilai adaptasi hunian (peninggian rumah) yang paling maksimal dilakukan masyarakat saat ini dalam menghadapi bencana banjir dan rob. Proses untuk mencapai tujuan ini adalah melalui observasi adaptasi hunian, wawancara stakeholder terkait adaptasi hunian, serta melalui kuesioner dilakukan terhadap 100 orang secara acak (proporsional stratified random sampling) kepada penduduk. Penelitian ini menggunakan pendekatan kuantitatif untuk data yang berasal dari kuesioner dapat diolah dan dianalisis menggunakan analisis multi kriteria. Berdasarkan penilaian yang telah dilakukan menggunakan variabel kerentanan, finansial, kelayakan hunian, sosial budaya, ekonomi kawasan, dan kapasitas teknis, bentuk adaptasi yang paling maksimal adalah bentuk adaptasi peninggian lantai pada seluruh ruangan dengan ketinggian $>50 \mathrm{~cm}$ dengan nilai 0.805 , peringkat kedua adalah bentuk adaptasi peninggian lantai disertai dengan pembangunan lantai dua yang mempunyai nilai 0,705 , dan peringkat ketiga adalah bentuk adaptasi peninggian lantai pada sebagian ruangan yang mempunyai nilai 0,700 .
\end{abstract}

Kata Kunci: Bencana Alam, Adaptasi Hunian, Penilaian Adaptasi.

[Title: Evaluation Of Community Adaptation in The Flood Prone Area, Case of Kemijen Village]. Kemijen urban village located in the coastal city of Semarang has a high level of disaster vulnerability. This situation forces people to adapt to the situation, for example, by elevating their homes. Given that this village is dominated by the low income communities, their adaption to this disaster might have limitation. Hence, the purpose of this study was to assess the maximum level of community adaptation in facing the flood disaster, particularly related to the elevation of the house. . This study conducted observation on adaptation of residential, interview with the relevant stakeholders, as well as collecting questionnaires on 100 respondents (proportional stratified random sampling). This study used a quantitative approach to gain data derived from questionnaires, then it processed and analyzed by using multi-criteria analysis. Based on the assessment that has been carried out by using variables on vulnerability: financial feasibility of residential, social, cultural, economic, as well as the regional and technical capacity, the community's adaptation is by elevating the floor in the entire rooms with a height $>50 \mathrm{~cm}$, or elevating the floor and construct the second floor, and elevating the floor in some rooms.

Keyword: Disaster; Housing Adaptation; Adaptation Assessment.

Cara mengutip: Kencana, Aufa Dirgahayu dan Yuliastuti, Nany. (2016). Penilaian Bentuk Adaptasi Masyarakat Terhadap Hunian di Kawasan Rawan Rob dan Banjir Kelurahan Kemijen. Jurnal Pengembangan Kota. Vol 4 (2): 186-196. DOI: 10.14710/jpk.4.2.186-196

\section{PENDAHULUAN}

Bentuk adaptasi masyarakat merupakan salah satu kajian kerentanan yang selama ini diartikan sebagai karakteristik dan situasi sebuah masyarakat, sistem, atau aset yang membuat mereka mudah terkena dampak merugikan dari sebuah bahaya atau dampak perubahan iklim (United Nations, 2009). Dalam mengkaji kerentanan, aspek yang dinilai yaitu berkaitan dengan pengurangan angka kerentanan tersebut sehingga mengindikasikan terciptanya suatu ketahanan terhadap bencana (Downing, Ringius, Hulme, \& Waughray, 1997) dan dengan melihat seberapa lama suatu bentuk adaptasi dapat memberikan manfaat (Mukheibir, 2008). Maksimal atau tidaknya adaptasi dapat dinilai dari kriteria finansial dengan melihat biaya yang dikeluarkan dalam suatu bentuk adaptasi
(Downing, dkk., 1997). Proses adaptasi hunian yang dilakukan biasanya disertai dengan peningkatan kondisi huniannya (Danianti \& Sariffuddin, 2015). Dalam menilai kelayakan hunian tersebut, dapat dilihat dari kondisi lantai, dinding, atap, dan sistem sanitasi (Astuti, 2015). Sementara itu, Pramita, Yasa, dan Marhaeni (2015) berpendapat bahwa penilaian kelayakan hunian tersebut dapat dilihat dari aspek kebersihan, ventilasi, luas bangunan, kualitas bangunan, kerapihan, dan kelengkapan ruangan. Penilaian bentuk adaptasi juga tak bisa

ISSN: 2337-7062 (Print), 2503-0361 (Online) @ 2016

This is an open access article under the CC-BY-NC-ND license (http://creativecommons.org/licenses/by-nc-sa/4.0/). - lihat halaman depan (c) 2016

*Email: aufa.dirgahayu@gmail.com

Diterima 8 Agustus 2016, disetujui 12 November 2016 
lepas dari dari aspek sosial budaya berkenaan dengan penerimaan masyarakat dan penerimaan oleh para pemangku pementingan atau stakeholders (Haque, Grafakos, \& Huijsman, 2012). Selain aspek di atas, penerimaan masyarakat juga mempunyai hubungan dengan bagaimana suatu bentuk adaptasi dapat direplikasi oleh semua elemen didalam masyarakat (Mukheibir, 2008). Kriteria ekonomi makro dalam penilaian adaptasi hunian berhubungan dengan bagaimana suatu bentuk adaptasi dapat menciptakan lapangan pekerjaan. Penciptaan lapangan pekerjaan dalam hubungannya dengan bentuk adaptasi adalah bagaimana proses adaptasi tersebut setidaknya dapat menyerap tenaga kerja di sekitarnya (Sariffuddin \& Wijaya, 2014). Hal ini penting agar suatu bentuk adaptasi tidak hanya bermanfaat bagi masyarakat yang melakukan kegiatan adaptasi tetapi juga bermanfaat kepada masyarakat sekitarnya karena penciptaan lapangan pekerjaan (Dumenu \& Obeng, 2016; Nordgren, Stults, \& Meerow, 2016). Sementara itu kapasitas teknis sangat penting untuk memastikan suatu bentuk adaptasi dapat berfungsi sebagaimana mestinya (Gohar \& Cashman, 2016; Tambo, 2016). Dari berbagai kriteria yang dapat dinilai tersebut kemudian diturunkan ke dalam indikator dan rentang nilai baik dari tiap indikator ataupun dari tiap kriteria seperti terlihat pada tabel 1.

Penelitian mengenai bentuk adaptasi masyarakat ini dilakukan di Kelurahan Kemijen yang terletak di pesisir Kota Semarang mengakibatkan kawasan ini sering dilanda bencana berupa rob (Marfai \& King, 2008b; Pradana \& Mussadun, 2013). Penyebab utama terjadinya bencana rob di Kelurahan Kemijen adalah efek perubahan iklim berupa peningkatan muka air laut (Marfai \& King, 2008a). Kenaikan muka air laut ini kemudian diperparah dengan adanya penurunan muka tanah yang tinggi $>8$ $\mathrm{cm} /$ tahun di Kelurahan Kemijen (Bappeda, 2011) sehingga dampak rob semakin meningkat setiap tahunnya. Selain rob wilayah ini juga rawan terhadap bencana banjir karena Kelurahan Kemijen dilalui Sungai Banger yaitu salah satu induk sungai yang memiliki tingkat endapan yang sangat tinggi (The Rockefeller Foundation, 2013). Kondisi ini menjadikan tingkat kerentanan di Kelurahan Kemijen yang berada pada kategori sedang pada 2010 dan meningkat pada kategori tinggi pada 2030 (Suhelmi, 2013).
Kelurahan Kemijen terletak di pesisir Kota Semarang, merupakan pusat perkembangan industri Kota Semarang. Karena letaknya yang sangat strategis dan mempunyai kerentanan terhadap bencana, telah banyak bantuan digelontorkan di Kelurahan Kemijen yang dananya kemudian bersama-sama digunakan oleh masyarakat untuk melakukan adaptasi (adaptasi secara kolektif). Akan tetapi menurut Suhelmi (2013) kemampuan adaptasi masyarakat Kelurahan Kemijen masih rendah. Untuk itu perlu melihat bentuk adaptasi lain yang menyebabkan kemampuan adaptasi masyarakat Kelurahan Kemijen tersebut rendah. Jika dilihat dari kondisi sosial ekonomi, penduduk Kelurahan Kemijen sebagian besar bermata pencaharian pada sektor formal menjadi buruh industri. Kondisi demikian tergolong dalam masyarakat berpenghasilan rendah (MBR) sehingga mempunyai keterbatasan pendanaan hunian. Keterbatasan pendanaan masyarakat pada adaptasi secara individu dan adaptasi institusional tersebut yang kemudian menyebabkan Kelurahan Kemijen memiliki kemampuan adaptasi yang rendah pada 2010 dan akan tetap rendah pada 2030 (Suhelmi, 2013). Hal ini tentunya akan menjadi tantangan terwujudnya program 100-0-100 di Kelurahan Kemijen khususnya mengentaskan kekumuhan di Kelurahan Kemijen pada tahun 2019.

Letak Kelurahan Kemijen yang rentan dapat terlihat dari hampir semua masyarakat yang melakukan adaptasi hunian (Yuliastuti \& Saraswati, 2014). Akan tetapi kemampuan adaptasi masyarakat masih rendah (Suhelmi, 2013). Kemampuan adaptasi masyarakat yang rendah tersebut dapat dipengaruhi oleh keberagaman bentuk adaptasi khususnya hunian yang dilakukan masyarakat. Hal ini dikarenakan dengan dana yang mereka miliki mereka harus membuat suatu bentuk adaptasi hunian dengan proporsi yang berbeda terhadap suatu kriteria adaptasi karena keterbatasan pengetahuan masyarakat. Dengan keterbatasan pengetahuan, dalam menentukan apakah suatu bentuk adaptasi hunian tersebut sudah maksimal kadang terdapat beberapa kriteria yang tidak diperhatikan oleh masyarakat. Sehingga dengan pengetahuan masyarakat saat ini belum adanya suatu konsensus mengenai suatu bentuk adaptasi yang paling maksimal. Hal ini kemudian yang menjadikan adaptasi hunian masyarakat secara 
keseluruhan menjadi kurang maksimal. Untuk itu penelitian ini bertujuan untuk mengkaji bentuk adaptasi masyarakat terhadap hunian yang paling maksimal dilakukan masyarakat saat ini di kawan rawan bencana rob dan banjir Kelurahan Kemijen.

Penelitian mengenai penilaian adaptasi terhadap bencana sudah banyak dilakukan. Akan tetapi penelitian-penelitian tersebut kebanyakan merupakan penilaian mengenai program yang akan dijalankan dan bukan merupakan evaluasi atau penilaian adaptasi yang telah dilakukan. Penelitian sebelumnya yang dilakukan oleh Danianti dan Sariffuddin (2015), Putra (2015), dan Marfai dan King (2008b) lebih banyak membahas mengenai penilaian adaptasi secara umum dan belum banyak mengupas penilaian adaptasi hunian.

\section{METODE PENELITIAN}

Penelitian ini menggunakan analisis multi kriteria. Sementara itu, pembobotan analisis Multi kriteria tersebut pada penelitian ini dihasilkan pada masa penelitian dengan menghitung rata-rata nilai kriteria yang lebih penting menurut masyarakat Kelurahan Kemijen. Pembobotan dilakukan agar tidak semua kriteria mempunyai nilai yang sama karena terdapat kriteria tertentu yang mempunyai tingkat kepentingan lebih tinggi dibandingkan dengan kriteria lainnya. Semakin tinggi tingkat kepentingan suatu bentuk adaptasi maka semakin tinggi bobotnya. Sebelum mengalikan dengan bobot, tiap bentuk adaptasi akan dinilai terlebih dahulu. Kriteria yang digunakan dalam penelitian ini antara lain antara lain meliputi kerentanan, finansial, kelayakan hunian, sosial budaya, ekonomi kawasan, serta kapasitas teknis (Haque, dkk., 2012)

Tabel 1 berfungsi untuk membentuk suatu standarisasi yang bertujuan agar yang tadinya antar kriteria mempunyai nilai yang rentangnya berbeda dapat disamakan rentangnya yaitu antara 0-1. Standarisasi angka 0-1 akan memudahkan peneliti untuk dapat membandingkan antar kriteria pada suatu bentuk adaptasi mana kriteria yang paling menonjol pada suatu bentuk adaptasi. Dalam melihat perbandingan tersebut maka dapat menggunakan diagram radar. Perbandingan tersebut juga digunakan untuk melihat kriteria mana yang lebih penting pada tiap bentuk adaptasi secara keseluruhan dibandingkan dengan kriteria lainnya sehingga didapatkan bobot dari tiap kriteria. Standarisasi nilai tersebut menggunakan rumus 1.

Tabel 1.

Bobot Kriteria Penilaian Adaptasi Hunian

\begin{tabular}{|c|c|c|c|c|}
\hline No & Kriteria & Indikator & $\begin{array}{l}\text { Nilai tiap } \\
\text { indikator }\end{array}$ & $\begin{array}{c}\text { Total nilai tiap } \\
\text { kriteria }\end{array}$ \\
\hline \multirow{2}{*}{1} & \multirow{2}{*}{ Kerentanan } & Pengurangan Kerentanan & $1-5$ & \multirow{2}{*}{$2-10$} \\
\hline & & Jangka Waktu Pengulangan Suatu Adaptasi & $1-5$ & \\
\hline 2 & Finansial & Besaran Biaya yang dikeluarkan & Juta & Juta \\
\hline \multirow{3}{*}{3} & \multirow{3}{*}{ Kelayakan Hunian } & Keselamatan & $3-9$ & \multirow{3}{*}{$7-18$} \\
\hline & & Kesehatan & $3-7$ & \\
\hline & & Kecukupan Luas Minimum & $1-2$ & \\
\hline \multirow{3}{*}{4} & \multirow{3}{*}{ Sosial Budaya } & Tingkat Replikasi & $1-5$ & \multirow{3}{*}{$3-11$} \\
\hline & & Tingkat Penerimaan Masyarakat & $1-3$ & \\
\hline & & Tingkat Penerimaan Stakeholder & $1-3$ & \\
\hline \multirow{2}{*}{5} & \multirow{2}{*}{ Ekonomi Kawasan } & Tingkat Penciptaan Lapangan Pekerjaan & $1-5$ & \multirow{2}{*}{$2-8$} \\
\hline & & Penyerapan Tenaga Kerja Sekitar & $1-3$ & \\
\hline 6 & Kapasitas Teknis & Kemampuan Tenaga Pembangunan & $1-3$ & $1-3$ \\
\hline
\end{tabular}

Sumber : Penulis, 2016 berdasarkan Penelitian Downing, dkk. (1997), Mukheibir (2008) dan Haque, dkk. (2012)

Skor Kriteria $=\frac{(\text { Nilai Total Kriteria }- \text { Nilai Terendah Kriteria })}{(\text { Nilai Terting } \text { I Kriteria-Nilai Terendah Kriteria })}$. 


\section{HASIL DAN PEMBAHASAN}

Bentuk adaptasi masyarakat terhadap hunian di Kelurahan Kemijen terbagi atas 5 bentuk adaptasi hunian yang dilakukan oleh masyarakat. Kelima bentuk adaptasi tersebut adalah adaptasi membuat barier, meninggikan lantai pada seluruh ruangan dengan ketinggian $>50 \mathrm{~cm}$, meninggikan lantai pada sebagian ruangan, meninggikan lantai pada seluruh ruangan dengan ketinggian $50 \mathrm{~cm}$, dan meninggikan lantai disertai dengan pembangunan lantai 2 . Bentuk adaptasi berupa peninggian lantai pada seluruh ruangan dengan ketinggian $>50 \mathrm{~cm}$ merupakan bentuk adaptasi yang populer dilakukan oleh masyarakat dengan persentase sebesar $39 \%$. Hal ini dikarenakan jika dilihat dari pendapatan masyarakat dominan Kelurahan Kemijen yaitu sebagai buruh bangunan, maka dalam waktu 5 tahun mereka dapat melakukan bentuk adaptasi ini dengan dana simpanan sebesar 30\% - 35\% dari total pendapatan mereka. Sementara itu bentuk adaptasi yang tidak banyak dilakukan adalah bentuk adaptasi meninggikan lantai disertai dengan pembangunan lantai 2 yaitu hanya dilakukan oleh sebesar $6 \%$ dari total 100 responden (lihat gambar $1)$.

Bentuk adaptasi berupa pembuatan barier merupakan bentuk adaptasi yang banyak dilakukan masyarakat yang tergolong tidak mampu (Kumalasari \& Yuliastuti, 2013). Hal itu dikarenakan bentuk adaptasi ini merupakan bentuk adaptasi yang paling sedikit mengeluarkan biaya pembangunan. Bentuk adaptasi ini berupa peninggian halaman depan disertai dengan pembuatan penghalang di depan pintu. Peninggian halaman depan ini dimaksudkan untuk dapat mengimbangi peninggian jalan yang dilakukan oleh pemerintah yang biasanya menyebabkan kondisi drainase menjadi dangkal. Kegiatan pembuatan barier ini merupakan kegiatan pembangunan yang sangat sederhana sehingga sebagian besar hunian yang melakukan kegiatan adaptasi ini tidak membutuhkan tenaga pembangunan untuk melakukan dan pemilik hunian akan melakukan pembangunan seorang diri.

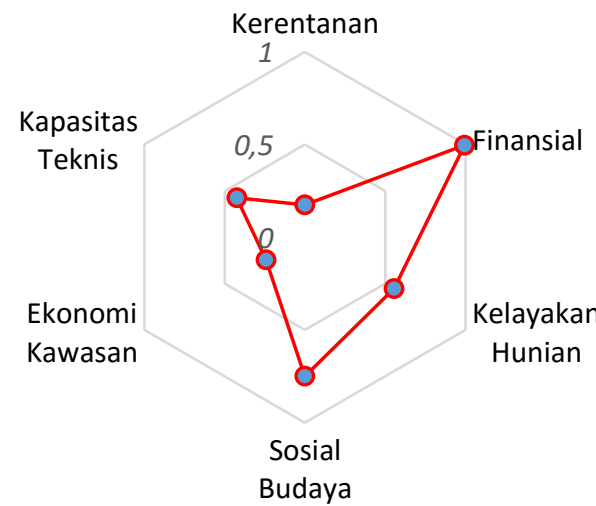

Gambar 1. Nilai pada Setiap Kriteria Adaptasi Pembuatan Barier

Bentuk adaptasi dengan membuat barier merupakan bentuk adaptasi dengan skor yang tinggi pada kriteria finansial $(0,994)$ dan pada kriteria sosial budaya $(0,75)$ sementara itu mempunyai kategori rendah yaitu pada kriteria ekonomi kawasan $(0,242)$ dan kriteria kerentanan $(0,175)$ seperti terlihat pada gambar 1 . Hal ini mengindikasikan bahwa bentuk adaptasi ini lebih mengutamakan kecukupan finansial dan bagaimana suatu bentuk adaptasi dapat diterima oleh sosial dan budaya masyarakat Kemijen. Bentuk adaptasi ini tidak memperhatikan bagaimana suatu bentuk adaptasi dapat menciptakan efek ekonomi kawasan serta efek pengurangan bencana pada jangka waktu yang panjang (lihat gambar 2 ).

Bentuk adaptasi berupa peninggian lantai pada seluruh ruangan dengan ketinggian $>50 \mathrm{~cm}$ adalah bentuk peninggian ruangan yang kebanyakan dilakukan setinggi $100 \mathrm{~cm}$ sebanyak $54 \%$ responden dan $46 \%$ sisanya melakukan peninggian lantai setinggi $150 \mathrm{~cm}$. Bentuk adaptasi ini yaitu dengan cara peninggian lantai pada seluruh ruangan termasuk fasilitas MCK. Bentuk adaptasi ini biasanya dilakukan setiap 5 tahun sekali mengikuti kegiatan peninggian jalan dan pada kurun waktu 1015 tahun biasanya warga akan meninggikan lantai disertai dengan peninggian atap. Dalam melakukan pembangunan adaptasi ini, sebagian besar masyarakat melakukan adaptasi dengan bantuan tenaga pembangunan karena adaptasi jenis ini memerlukan waktu yang relatif lama dalam proses pembangunannya apalagi jika sampai meninggikan atap hunian. 


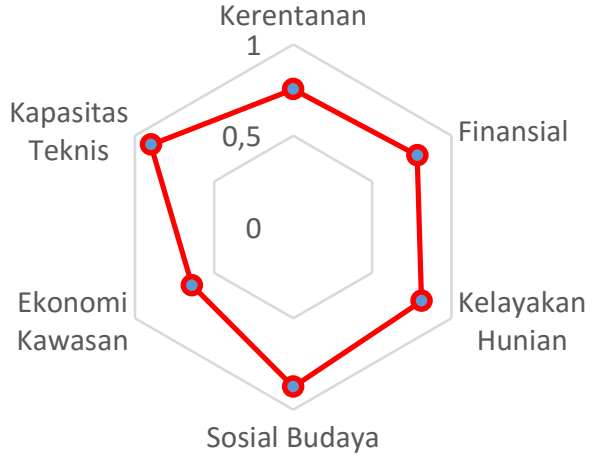

Gambar 2. Nilai pada Setiap Kriteria Adaptasi Peninggian Lantai pada Seluruh Ruangan dengan Ketinggian $>50 \mathrm{~cm}$

Bentuk adaptasi dengan meninggikan lantai pada seluruh ruangan dengan ketinggian $>50 \mathrm{~cm}$ mempunyai skor yang relatif seimbang dibandingkan dengan bentuk adaptasi lainnya. Hal ini dapat terlihat dari 5 kriteria pada bentuk adaptasi ini mempunyai nilai yang tinggi dan 1 kriteria lagi yaitu kriteria ekonomi kawasan $(0,640)$ mempunyai nilai termasuk pada kategori menengah seperti terlihat pada gambar 2. Hal ini mengindikasikan adaptasi jenis ini hampir memperhatikan semua aspek yang berkenaan dalam melakukan suatu bentuk adaptasi yaitu bagaimana suatu bentuk adaptasi dapat mengurangi kerentanan, dapat sesuai dengan kemampuan finansial mereka, dapat juga meningkatkan nilai kelayakan hunian mereka, sesuai dengan nilai sosial dan budaya masyarakat Kelurahan Kemijen serta juga memperhatikan bagaimana suatu bentuk adaptasi dapat berfungsi sebagaimana mestinya. Akan tetapi bentuk adaptasi ini kurang memperhatikan efek adaptasi tersebut kepada ekonomi kawasan.

Bentuk adaptasi berupa peninggian lantai pada sebagian ruangan adalah bentuk kegiatan adaptasi dengan cara meninggikan lantai pada ruangan yang dianggap penting sehingga tidak mengganggu kegiatan bermukim penghuni hunian itu. Biasanya yang dilakukan peninggian adalah bagian depan hunian, ruang tamu, ruang keluarga, dan ruang tidur. Untuk itu kebanyakan hunian yang melakukan bentuk adaptasi ini bagian belakangnya akan terendam air saat banjir dan rob tiba. Untuk sebagian hunian, mereka akan melakukan peninggian bagian depan hunian, ruang tamu, dan ruang tidur. Sementara itu untuk bagian lainnya biasanya dilakukan peninggian akan tetapi ketinggiannya setengah dari ketinggian bagian hunian lainnya. Misalnya untuk bagian depan ketinggian bisa mencapai $100 \mathrm{~cm}$, akan tetapi untuk bagian belakang hanya $50 \mathrm{~cm}$. Bentuk adaptasi ini dapat bertahan 4-5 tahun. Sebagian masyarakat yang melakukan bentuk adaptasi ini memerlukan bantuan dari tenaga pembangunan karena sebagian masyarakat meninggikan lantai hingga $150 \mathrm{~cm}$ (lihat gambar 3).

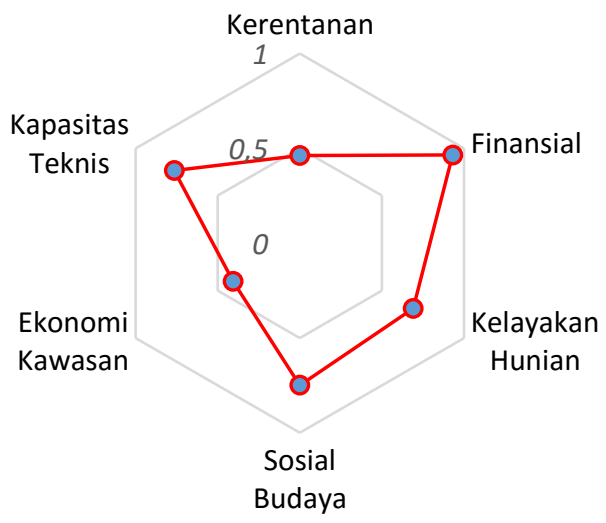

Gambar 3. Nilai pada Setiap Kriteria Adaptasi Peninggian Lantai pada Sebagian Ruangan.

Bentuk adaptasi meninggikan lantai pada sebagian ruangan mempunyai skor kriteria terbesar yaitu pada kriteria finansial $(0,93)$ dan skor terkecil pada kriteria ekonomi kawasan $(0,41)$ seperti terlihat pada gambar 3. Jika dilihat secara menyeluruh, keempat kriteria pada bentuk adaptasi ini termasuk pada kategori tinggi dan kedua kriteria lainnya termasuk pada kategori menengah. Hal ini mengindikasikan bahwa bentuk adaptasi ini lebih memperhatikan kriteria finansial $(0,93)$, kelayakan hunian $(0,689)$, sosial budaya $(0,75)$, dan kapasitas teknis $(0,765)$ dan kurang memperhatikan kategori pengurangan kerentanan $(0,461)$ dan ekonomi kawasan $(0,405)$. Jika dilihat dari skor terbesar yaitu pada kriteria finansial dan dua kriteria pada kategori menengah dapat disimpulkan bahwa bentuk adaptasi ini lebih memikirkan bagaimana tercipta suatu keefektifan biaya dengan biaya yang mereka miliki dengan mempekerjakan tenaga pembangunan seminimal mungkin dengan tujuan agar hunian mereka setidaknya tahan terhadap bencana pada beberapa bagian (ruang yang dianggap penting).

Bentuk adaptasi berupa peninggian lantai pada seluruh ruangan dengan ketinggian $50 \mathrm{~cm}$ pada hakikatnya bentuk sama dengan peninggian lantai 
pada seluruh ruangan setinggi $>50 \mathrm{~cm}$ akan tetapi memiliki angka pengurangan terhadap bencana dan biaya yang berbeda jauh dari bentuk adaptasi tersebut. Dalam melakukan adaptasi ini biasanya warga melakukannya secara bertahap mulai dari bagian depan sampai bagian belakang selama satu tahun. Oleh karena itu kebanyakan masyarakat yang melakukan adaptasi ini tidak membutuhkan tenaga pembangunan karena dapat melakukan pembangunan sendiri dalam waktu yang singkat. Oleh karena ketinggiannya yang hanya $50 \mathrm{~cm}$, masyarakat melakukan adaptasi ini dalam kurun waktu 4 tahun sekali (lihat gambar 4).

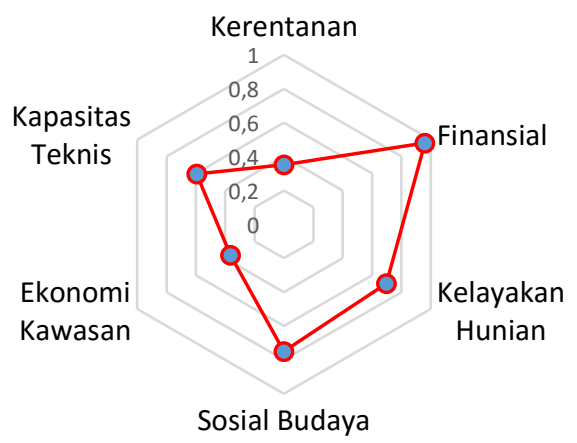

Gambar 4. Nilai pada Setiap Kriteria Adaptasi Peninggian Lantai pada Seluruh Ruangan dengan Ketinggian $50 \mathrm{~cm}$

Bentuk adaptasi meninggikan lantai pada seluruh ruangan dengan ketinggian $50 \mathrm{~cm}$ mempunyai skor kriteria yang berimbang karena ketiga kriteria berada pada kategori menengah (skor 0,33-0,66) dan ketiga kriteria lagi berada pada kategori tinggi (skor $>0,66$ ) seperti terlihat pada gambar 4 . Kriteria yang berada pada kategori menengah pada bentuk adaptasi ini adalah kriteria kerentanan $(0,351)$, ekonomi kawasan $(0,365)$, dan kapasitas teknis $(0,595)$ sedangkan kriteria finansial $(0,960)$, kelayakan hunian $(0,699)$, dan sosial budaya $(0,75)$ merupakan kriteria yang berada pada kategori tinggi. Sementara itu jika melihat kepada skor terbesar yaitu pada kriteria finansial $(0,96)$ dan yang paling kecil skornya adalah kriteria kerentanan $(0,35)$ seperti terlihat pada gambar 4 . Hal ini mengindikasikan bahwa bentuk adaptasi ini lebih mementingkan bagaimana kemampuan keuangan mereka cukup untuk melakukan adaptasi walaupun pengurangan kerentanan yang mereka peroleh tidak signifikan. Kemudian juga dalam melakukan adaptasi, kebanyakan masyarakat melakukan penghematan dana karena mereka memperhatikan kemampuan finansial mereka dengan cara tidak mempekerjakan tenaga pembangunan yang otomatis mereka sendiri yang melakukan pembangunan sehingga efek ekonomi kawasan dan kapasitas teknis pada adaptasi ini berada pada kategori menengah. Kemudian juga dalam melakukan adaptasi, masyarakat yang melakukan adaptasi ini juga memperhatikan nilai sosial budaya masyarakat dan kelayakan hunian.

Bentuk adaptasi yang paling sedikit dilakukan di Kelurahan Kemijen adalah bentuk adaptasi berupa peninggian lantai disertai dengan pembangunan lantai dua. Hal ini dikarenakan bentuk adaptasi ini memerlukan dana yang banyak karena bentuknya yaitu berupa renovasi hunian total sedangkan kebanyakan masyarakat Kelurahan Kemijen tergolong masyarakat berpenghasilan rendah. Bentuk adaptasi ini dapat bertahan lama karena ketinggian lantai dasar yang mencapai $150 \mathrm{~cm}$ dan keberadaan lantai dua sehingga akan dapat bertahan dari adanya banjir dan rob selama 7-8 tahun. Jika dalam kurun waktu 20 tahun maka biasanya jalan hampir sama dengan ketinggian lantai dua sehingga lantai dua dapat dijadikan sebagai lantai utama dan lantai 1 tidak dihuni lagi. Dalam melakukan bentuk adaptasi ini sangat diperlukan perekrutan tenaga pembangunan dalam jumlah besar agar proses pembangunan dapat diselesaikan dalam jangka waktu yang singkat (lihat gambar 5).

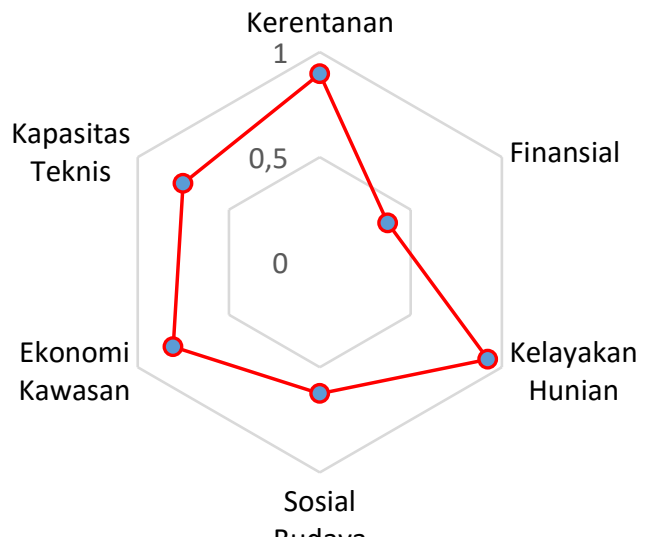

Gambar 5. Nilai pada Setiap Kriteria Adaptasi Peninggian Lantai disertai pembangunan lantai 2 .

Bentuk adaptasi meninggikan lantai disertai dengan pembangunan lantai dua mempunyai nilai yang berkebalikan dengan bentuk adaptasi pembuatan barier dimana bentuk adaptasi ini mempunyai kriteria yang berada pada kategori tinggi yaitu 
kriteria kerentanan $(0,896)$, kelayakan hunian $(0,924)$, ekonomi kawasan $(0,805)$, dan kapasitas teknis $(0,75)$ sedangkan kriteria lainnya yang pada adaptasi pembuatan barier berada pada kategori tinggi pada adaptasi ini kriteria tersebut berada pada kategori menengah (finansial dengan skor 0,373 dan sosial budaya dengan skor 0,625 ) seperti terlihat pada gambar 5 . Hal ini dikarenakan bentuk adaptasi ini dilakukan oleh masyarakat menengah ke atas yang notabene kurang memperhatikan kemampuan finansial karena mereka memiliki kecukupan finansial karena bagi mereka bagaimana suatu bentuk adaptasi dapat menciptakan pengurangan kerentanan yang signifikan dan dapat bekerja sebagaimana mestinya adalah nilai mutlak sehingga dalam pembangunan bentuk adaptasi ini memberikan efek ekonomi kawasan yang cukup tinggi. Selain sangat memperhatikan pengurangan kerentanan, bentuk adaptasi ini juga sangat memperhatikan kelayakan hunian mereka sehingga apa yang mereka lakukan kurang sesuai dengan nilai sosial budaya di Kelurahan Kemijen sehingga nilai sosial dan budaya di Kelurahan Kemijen berada pada kategori menengah.

Skor-skor pada gambar 1-5 diatas kemudian digunakan untuk melihat bobot dari tiap kriteria. Cara menghitung bobot dari tiap kriteria adalah dengan menghitung rata-rata skor yang telah distandarisasi pada tiap kriteria. Hal tersebut dilakukan karena skor tersebut mencerminkan bagaimana derajat kepentingan tiap kriteria dibandingkan dengan kriteria lainnya. Derajat kepentingan tersebut diperoleh dengan membagi antara skor rata-rata kriteria dengan jumlah skor rata-rata semua kriteria sehingga diperoleh bobot dari tiap kriteria. Bobot dari tiap kriteria tersebut antara lain seperti tabel 2.

Tabel 2.

Nilai Rata-rata dan Bobot dari Tiap Kriteria

\begin{tabular}{lcc}
\hline \multicolumn{1}{c}{ Kriteria } & Nilai Rata-rata & Bobot \\
\hline Kerentanan & 0,532 & $13,14 \%$ \\
\hline Finansial & 0,846 & $20,90 \%$ \\
\hline Kelayakan Hunian & 0,685 & $16,91 \%$ \\
\hline Sosial Budaya & 0,703 & $17,37 \%$ \\
\hline Ekonomi Kawasan & 0,500 & $12,35 \%$ \\
\hline Kapasitas Teknis & 0,783 & $19,33 \%$ \\
\hline Total & 4,048 & $100,00 \%$ \\
\hline
\end{tabular}

Kriteria yang mempunyai bobot tertinggi adalah kriteria finansial dengan bobot 20,90 \% seperti terlihat pada tabel 2 . Kriteria ini mempunyai nilai tertinggi karena 7 dari 8 bentuk adaptasi lebih mementingkan kriteria ini dalam proses pemilihan bentuk adaptasi yang akan dilakukan. Hal ini dikarenakan keterbatasan pendanaan hunian di Kelurahan Kemijen sehingga dalam proses pemilihan bentuk adaptasi apa yang akan dilakukan oleh masyarakat hal yang menjadi bahan perhitungan utama mereka adalah kemampuan finansial dan agar biaya yang dikeluarkan dapat seefektif mungkin (Downing, dkk., 1997).

Sementara itu kriteria yang mempunyai tingkat kepentingan kedua yaitu kapasitas teknis dengan bobot $19,33 \%$ seperti terlihat pada tabel 2 . Hal ini mengindikasikan bahwa masyarakat Kelurahan Kemijen telah berpikir rasional yaitu bagaimana adaptasi yang mereka lakukan dapat berjalan sebagaimana mestinya walaupun mereka harus mengeluarkan dana lebih untuk membiayai tenaga pembangunan (Haque, dkk., 2012). Sementara itu kriteria yang mempunyai nilai terendah yaitu kriteria ekonomi kawasan dengan bobot 12,35\% seperti terlihat pada tabel 2 . Kriteria ini mempunyai nilai terkecil karena 6 dari 8 adaptasi dalam melakukan adaptasi kurang memperhatikan bagaimana suatu adaptasi yang mereka lakukan dapat memiliki efek ekonomi kawasan dan malah terdapat satu bentuk adaptasi yang sama sekali tidak memperhatikan bagaimana efek dari adanya adaptasi bagi ekonomi kawasan. Kondisi ini dikarenakan kebanyakan dari bentuk adaptasi lebih memikirkan bagaimana kemampuan finansial mereka dapat mencukupi kegiatan adaptasi yang mereka lakukan sehingga kebanyakan dari mereka melakukan adaptasi sendiri sehingga kurang tercipta efek adaptasi yang signifikan tersebut kepada ekonomi kawasan di Kelurahan Kemijen.

Skor-skor pada gambar 1, gambar 2, gambar 3, gambar 4 dan gambar 5 kemudian dikalikan dengan besaran pembobotan tiap kriteria pada tabel 2 . Kemudian skor totalnya akan dibandingkan bentuk adaptasi mana yang paling maksimal. Perbandingan yang ada kemudian dapat diturunkan lagi menurut tingkat pendapatan masyarakat yaitu tingkat pendapatan masyarakat berpenghasilan rendah dengan minimum pendapatan 1,5 juta rupiah, rumah tangga miskin dengan pendapatan 600 ribu 
Tabel 3.

Total Skor dan Peringkat Bentuk Adaptasi Hunian

\begin{tabular}{|c|c|c|c|c|c|c|c|c|}
\hline Bentuk Adaptasi & Kerentanan & Finansial & $\begin{array}{c}\text { Kelayakan } \\
\text { Hunian }\end{array}$ & $\begin{array}{c}\text { Sosial } \\
\text { Budaya }\end{array}$ & $\begin{array}{l}\text { Ekonomi } \\
\text { Kawasan }\end{array}$ & $\begin{array}{c}\text { Kapasitas } \\
\text { Teknis } \\
\end{array}$ & \multirow{2}{*}{$\begin{array}{l}\text { Total } \\
\text { Skor }\end{array}$} & \multirow[t]{2}{*}{ Peringkat } \\
\hline Bobot & $13,14 \%$ & $20,90 \%$ & $16,91 \%$ & $17,37 \%$ & $12,35 \%$ & $19,33 \%$ & & \\
\hline Membuat Barier & 0,023 & 0,208 & 0,094 & 0,130 & 0,030 & 0,082 & 0,567 & 5 \\
\hline $\begin{array}{l}\text { Meninggikan Lantai } \\
\text { Seluruhnya > } 50 \mathrm{~cm}\end{array}$ & 0,099 & 0,164 & 0,137 & 0,152 & 0,079 & 0,174 & 0,805 & 1 \\
\hline $\begin{array}{l}\text { Meninggikan Lantai } \\
\text { Sebagian }\end{array}$ & 0,061 & 0,194 & 0,117 & 0,130 & 0,050 & 0,148 & 0,700 & 3 \\
\hline $\begin{array}{l}\text { Meninggikan Lantai } \\
\text { Seluruhnya } 50 \mathrm{~m}\end{array}$ & 0,046 & 0,201 & 0,118 & 0,130 & 0,045 & 0,115 & 0,655 & 4 \\
\hline $\begin{array}{l}\text { Meninggikan Lantai dan } \\
\text { Membangun Lantai } 2\end{array}$ & 0,118 & 0,078 & 0,156 & 0,109 & 0,099 & 0,145 & 0,705 & 2 \\
\hline
\end{tabular}

rupiah hingga 1,5 juta rupiah, serta masyarakat tidak berdaya dengan pendapatan dibawah 600 ribu rupiah.

Bentuk adaptasi yang memiliki skor terbesar yaitu bentuk adaptasi peninggian lantai pada seluruh ruangan dengan ketinggian $>50 \mathrm{~cm}$. Sementara itu skor terbesar kedua yaitu bentuk adaptasi berupa meninggikan lantai disertai dengan pembangunan lantai dua dengan total skor 0,705 kemudian bentuk adaptasi berupa meninggikan lantai pada sebagian ruangan dengan skor total 0,700 . Jika dilihat dari nilai tersebut maka bentuk adaptasi berupa peninggian lantai pada seluruh ruangan dengan ketinggian $>50 \mathrm{~cm}$ adalah bentuk adaptasi yang paling maksimal dilakukan oleh masyarakat. Hal ini dikarenakan bentuk adaptasi ini mempunyai keunggulan jika kriteria-kriteria tersebut dikombinasikan.

Keunggulan bentuk adaptasi ini dibandingkan dengan bentuk adaptasi yaitu pada kriteria sosial budaya dan kapasitas teknis sedangkan pada kriteria lainnya rata-rata bentuk adaptasi ini mempunyai nilai terbesar kedua. Bentuk adaptasi berupa meninggikan lantai pada seluruh ruangan dengan ketinggian $>50 \mathrm{~cm}$ dapat dilakukan oleh masyarakat berpenghasilan yang $\geq R p \quad 1.900 .000$ karena masyarakat menggunakannya sebesar $30 \%$ $35 \%$ dari total pendapatan mereka per bulan seperti pendapat Hulchanski (1995) untuk membiayai perbaikan hunian mereka. Jika dengan pendapatan minimal 1,5 maka mereka dapat mengumpulkan biaya sebesar 27 juta Rupiah jika hanya menggunakan pendapatan bulanan mereka sebesar $30 \%$ yang artinya dapat membiayai bentuk adaptasi berupa meninggikan lantai pada seluruh ruangan dengan ketinggian $>50 \mathrm{~cm}$ yang minimum hanya menghabiskan dana 25 juta Rupiah pada kurun waktu 5 tahun. Sementara itu masyarakat dengan pendapatan 600 ribu Rupiah - 1,5 juta direkomendasikan untuk melakukan bentuk adaptasi berupa peninggian lantai pada sebagian ruangan yang menghabiskan dana minimum 10 juta Rupiah karena dengan minimum pendapatan 600 ribu Rupiah dengan total $\mathrm{Rp}$ 10.238.000. Sementara itu, untuk mereka dengan pendapatan di bawah 600 ribu rupiah atau tergolong sangat miskin dianjurkan untuk mendapatkan bantuan program bedah rumah atau jika mereka tidak mendapatkannya direkomendasikan untuk melakukan bentuk adaptasi peninggian lantai pada seluruh ruangan dengan ketinggian $50 \mathrm{~cm}$.

Dari total skor pada tabel 3 kemudian dilihat bagaimana persebaran bentuk adaptasi yang dilakukan masyarakat per RW untuk dapat dinilai tingkat adaptasi masyarakat. Persebaran tersebut dapat dilihat dari bentuk adaptasi yang dilakukan oleh masyarakat pada tiap RW kemudian tiap adaptasi diberikan nilai sesuai dengan nilai pada kolom total skor pada tabel 3. 


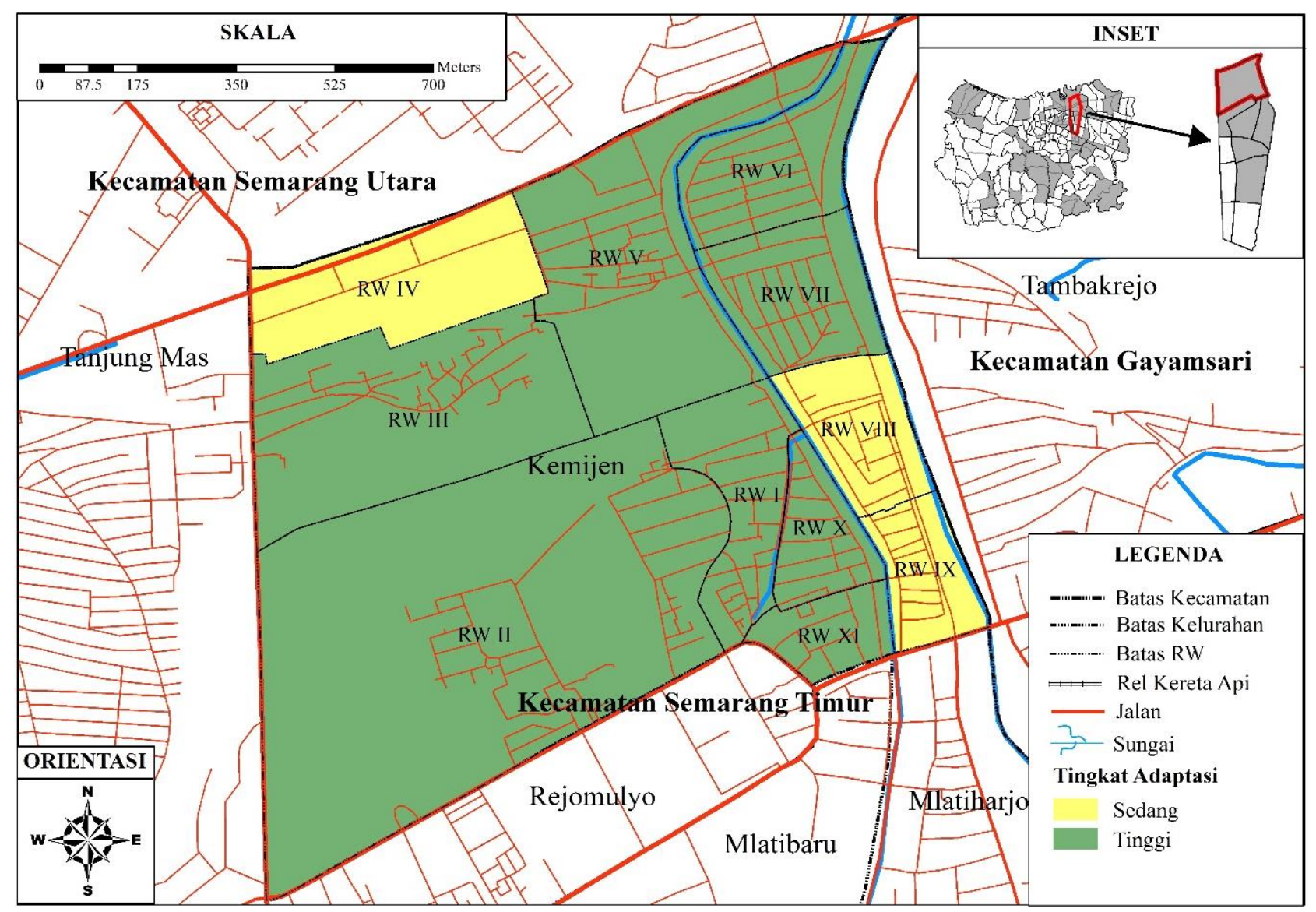

Gambar 6. Peta Tingkat Adaptasi Masyarakat Terhadap Hunian Per RW di Kelurahan Kemijen

Pada gambar 6 dapat terlihat bahwa mayoritas RW di Kemijen mempunyai tingkat adaptasi pada kategori tinggi yang dapat dilihat dari 8 RW $(73 \%)$ yang mempunyai skor $x$ bobot total $>0,666$. Ketiga RW lainnya mempunyai tingkat adaptasi menengah pada Kelurahan Kemijen yaitu RW IV yang mempunyai skor rata-rata 0,635, RW VIII $(0,655)$, dan RW IX yang mempunyai skor rata-rata 0,651 . Hal ini menunjukkan bahwa Kelurahan Kemijen mempunyai peluang yang cukup besar untuk mencapai 0\% permukiman kumuh pada tahun 2019 karena sebagian besar hunian di Kelurahan Kemijen telah mampu adaptif.

Akan tetapi dalam mencapai hal tersebut diperlukan dorongan dari berbagai pihak agar kemampuan adaptasi pada ketiga RW yang mempunyai kemampuan adaptasi pada tingkat menengah tersebut dapat meningkat menjadi kategori tinggi sebelum tahun 2019. Dorongan yang diperlukan pada ketiga RW tersebut yaitu melalui program bedah rumah yang mekanismenya dilakukan dengan cara program bedah rumah yang dilakukan oleh BKM. Selain ketiga RW tersebut, juga diperlukan bantuan bagi hunian yang tidak mampu beradaptasi ataupun hunian tidak layak huni yang tersebar di Kelurahan Kemijen. Dengan adanya program bedah rumah yang notabene akan meningkatkan kemampuan finansial, maka juga akan meningkatkan kapasitas teknis, kelayakan hunian, dan pengurangan terhadap bencana yang signifikan dimana ketiga kriteria inilah yang menyebabkan ketiga RW ini berada pada tingkat adaptasi menengah.

Penciptaan kapasitas teknis disebabkan oleh perekrutan tenaga pembangunan yang dapat dilakukan oleh masyarakat sehingga dengan perekrutan tersebut selain tercipta peningkatan kapasitas teknis juga tercipta peningkatan ekonomi kawasan Kelurahan Kemijen. Sementara itu dengan adanya program bedah rumah, masyarakat mendapatkan pilihan yang lebih banyak dalam melakukan adaptasi karena kapasitas pembiayaan yang mereka miliki juga menjadi lebih besar yang membawa dampak kepada pemilihan bentuk adaptasi yang mempunyai nilai pengurangan 
kerentanan yang lebih tinggi dibandingkan dengan adaptasi yang mereka lakukan saat ini.

\section{KESIMPULAN}

Bentuk adaptasi masyarakat terhadap bencana banjir dan rob pada hunian mereka pada Kelurahan Kemijen dibagi menjadi 5 jenis yaitu membuat barier, meninggikan lantai pada seluruh ruangan dengan ketinggian $>50 \mathrm{~cm}$, meninggikan lantai pada sebagian ruangan, meninggikan lantai pada seluruh ruangan dengan ketinggian $50 \mathrm{~cm}$, dan meninggikan lantai disertai dengan pembangunan lantai 2.

Bentuk adaptasi berupa peninggian lantai pada seluruh ruangan dengan ketinggian $>50 \mathrm{~cm}$ merupakan bentuk adaptasi yang populer. Sedangkan bentuk adaptasi yang paling sedikit dilakukan adalah meninggikan lantai disertai dengan pembangunan lantai 2 karena membutuhkan biaya yang tinggi sementara kebanyakan dari masyarakat Kelurahan Kemijen adalah MBR.Jika dilihat semua kriteria per bentuk adaptasi, bentuk adaptasi berupa peninggian lantai pada seluruh ruangan dengan ketinggian $>50 \mathrm{~cm}$ memiliki skor yang terbilang tinggi pada kelima kriteria dan merupakan bentuk adaptasi yang paling banyak memperhatikan kriteria yang digunakan untuk menilai bentuk adaptasi tersebut.

Sementara itu bentuk adaptasi yang kurang memperhatikan banyak kriteria yang digunakan dalam penilaian adalah adaptasi pembuatan barier dimana dua kriterianya termasuk dalam kategori tinggi, kedua kriteria lainnya termasuk dalam kategori menengah, dan kedua kriteria lagi termasuk dalam kategori rendah. Berdasarkan penilaian yang telah dilakukan menggunakan variabel kerentanan, finansial, kelayakan hunian, sosial budaya, ekonomi kawasan, dan kapasitas teknis, bentuk adaptasi yang paling maksimal adalah bentuk adaptasi peninggian lantai pada seluruh ruangan dengan ketinggian $>50 \mathrm{~cm}$ dengan nilai 0.805 , peringkat kedua adalah bentuk adaptasi peninggian lantai disertai dengan pembangunan lantai dua yang mempunyai nilai 0,705 dan peringkat ketiga adalah bentuk adaptasi peninggian lantai pada sebagian ruangan yang mempunyai nilai 0,700 .

\section{DAFTAR PUSTAKA}

Astuti, S. P. (2015). Implementasi Kebijakan Program Bedah Rumah Kota Bandar Lampung Tahun 2014. Universitas Lampung, Bandar Lampung.

Bappeda. (2011). Rencana Tata Ruang Wllayah Kota Semarang Tahun 2011-2031. Semarang: Bappeda Kota Semarang.

Danianti, R. P., \& Sariffuddin, S. (2015). Tingkat kerentanan masyarakat terhadap bencana banjir di Perumnas Tlogosari, Kota Semarang. Jurnal Pengembangan Kota, 3(2), 90-99. doi: http://dx.doi.org/10.14710/jpk.3.2.90-99

Downing, T. E., Ringius, L., Hulme, M., \& Waughray, D. (1997). Adapting to Climate Change in Africa. Mitigation and Adaptation Strategies for Global Change, 2(1), 19-44. doi: http://dx.doi.org/10.1023/b:miti.0000004663. 31074.64

Dumenu, W. K., \& Obeng, E. A. (2016). Climate change and rural communities in Ghana: Social vulnerability, impacts, adaptations and policy implications. Environmental Science \& Policy, 55, Part 1, 208-217. doi: http://dx.doi.org/10.1016/j.envsci.2015.10.010

Gohar, A. A., \& Cashman, A. (2016). A methodology to assess the impact of climate variability and change on water resources, food security and economic welfare. Agricultural Systems, 147, 51-64.

doi: http://dx.doi.org/10.1016/j.agsy.2016.05.008

Haque, A. N., Grafakos, S., \& Huijsman, M. (2012). Participatory integrated assessment of flood protection measures for climate adaptation in Dhaka. Environment and Urbanization, 24(1), 197-213.

doi: http://dx.doi.org/10.1177/0956247811433538

Kumalasari, N. R., \& Yuliastuti, N. (2013). Bentuk Adaptasi Masyarakat Terhadap Banjir Di Kampung Purwodinatan dan Jurnatan, Kota Semarang. Universitas Diponegoro, Semarang.

Marfai, M. A., \& King, L. (2008a). Coastal flood management in Semarang, Indonesia. Environmental Geology, 55(7), 1507-1518. doi: http://dx.doi.org/10.1007/s00254-007-1101-3

Marfai, M. A., \& King, L. (2008b). Potential vulnerability implications of coastal inundation due to sea level rise for the coastal zone of Semarang city, Indonesia. Environmental Geology, 54(6), 12351245. doi: http://dx.doi.org/10.1007/s00254007-0906-4

Mukheibir, P. (2008). Water Resources Management Strategies for Adaptation to Climate-Induced Impacts in South Africa. Water Resources 
Management, 22(9), 1259-1276. doi: http://dx.doi.org/10.1007/s11269-007-9224-6

Nordgren, J., Stults, M., \& Meerow, S. (2016). Supporting local climate change adaptation: Where we are and where we need to go. Environmental Science \& Policy, 66, 344-352. doi: http://dx.doi.org/10.1016/j.envsci.2016.05.006

Pradana, A. B., \& Mussadun. (2013). Faktor-faktor yang mempengaruhi preferensi masyarakat untuk tetap bertempat tinggal di kawasan bencana rob Kelurahan Kemijen Kecamatan Semarang Timur Kota Semarang. Ruang, 2(1), 361-370.

Pramita, A. L., Yasa, I., \& Marhaeni, A. (2015). Peranan Dana Bantuan Sosial Terhadap Kualitas Rumah Masyarakat Miskin Melalui Program Bedah Rumah Di Kabupaten Buleleng. E-Jurnal Ekonomi dan Bisnis Universitas Udayana, 4(2), 106-124.

Putra, A. P. (2015). Mapping Tsunami Vulnerability For Mataram City In Lombok Island - Indonesia: A Physical And Socioeconomic Assessment. Jurnal Pengembangan Kota, 3(1), 60-79. doi: http://dx.doi.org/10.14710/jpk.3.1.60-79

Sariffuddin, S., \& Wijaya, A. P. (2014). Pola Adaptasi Masyarakat Pesisir Genuk Kota Semarang. Tataloka, 16(4), 245-253. doi: http://dx.doi.org/10.14710/tataloka.16.4.245253
Suhelmi, I. R. (2013). Pemetaan Kapasitas Adaptif Wilayah Pesisir Semarang dalam Menghadapi Genangan Akibat Kenaikan Muka Air Laut dan Perubahan Iklim. Forum Geografi, 27(1), 81-92.

Tambo, J. A. (2016). Adaptation and resilience to climate change and variability in north-east Ghana. International Journal of Disaster Risk Reduction, 17, 85-94. doi: http://dx.doi.org/10.1016/j.ijdrr.2016.04.005

The Rockefeller Foundation. (2013). ACCCRN City Projects. Asian Cities Climate Change Resilience Network (ACCCRN) (doi: http://www.rockefellerfoundation.org/uploads /files/8ff925b8-2254-4b71-a7fb6082464b844e-acccrn-cities.pdf). Bangkok, Thailand.

United Nations. (2009). UNISDR Terminology on Disaster Risk Reduction. Geneva, Switzerland: United Nations International Strategy for Disaster Reduction.

Yuliastuti, N., \& Saraswati, N. (2014). Environmental Quality in Urban Settlement: The Role of Local Community Association in East Semarang Subdistrict. Procedia - Social and Behavioral Sciences, 135, 31-35. doi: http://dx.doi.org/10.1016/j.sbspro.2014.07.32 1 